\title{
Enhancement of the Surface Smoothness of Cu Ribbon for Solar Cell Modules
}

\author{
$\mathrm{Tae}$ Sik $\mathrm{Cho}^{\dagger}$ \\ Department of Nano Materials Engineering, Kyungpook National University, Sangju 742-711, Korea \\ Chul-Sik Cho \\ Laboratory, Sanko Korea Co., Gumi 730-853, Korea
}

Received April 25, 2014; Revised October 27, 2014; Accepted December 11, 2014

\begin{abstract}
We studied the relationship between the surface smoothness of the internal $\mathrm{Cu}$ ribbon and the morphology of the $\mathrm{Sn}-\mathrm{Pb}$ plating layer for solar cell modules. A bumpy surface was observed on the surface of the solar ribbon, which caused irregular reflection of light. Large, $\mathrm{Pb}$-rich, primary $\alpha$-phases were found below the convex surface of the solar ribbon, passing from the surface of the internal $\mathrm{Cu}$ ribbon to the surface of the plating layer. The primary $\alpha$-phases heterogeneously nucleated on the convex surface of the $\mathrm{Cu}$ ribbon, and then largely grew to the convex surface of the plating layer. The restriction of the primary $\alpha$-phase's formation was enabled by enhancing the smoothness of the $\mathrm{Cu}$ ribbon's surface; it was also possible to increase the adhesive strength and decrease contact resistance. We confirmed that the solar ribbon's surface smoothness depends on the internal Cu ribbon's surface smoothness.
\end{abstract}

Keywords: Solar ribbon, Sn-Pb solder, Surface smoothness, Morphology, Energy materials

\section{INTRODUCTION}

The importance of soldering is increasing due to the rapid growth of electronic packaging industries [1-3]. Lead-containing solders $(\mathrm{Sn}-\mathrm{Pb})$ have been widely used as low temperature joining alloys because of their good combination of process attributes, convenient material properties, and low cost [4,5]. However, concerns about lead toxicity have resulted in the ban of leadcontaining solders for use in electronic devices and components [3]. Therefore, establishing a lead-free solder, such as Sn-Ag, Sn$\mathrm{Ag}-\mathrm{Cu}, \mathrm{Sn}-\mathrm{Cu}$, and $\mathrm{Sn}-\mathrm{Zn}$ solders has become a critical issue [6-8].

Meanwhile, a solar ribbon is widely used as an electric wire to form a connection between cells in a solar module [9], as shown in Fig. 1. Solar ribbons are generally classified into two types: interconnector and bus-bar ribbons [9]. A solar ribbon is fab-

${ }^{\dagger}$ Author to whom all correspondence should be addressed: E-mail: cts@knu.ac.kr

Copyright (C2015 KIEEME. All rights reserved.

This is an open-access article distributed under the terms of the Creative Commons Atribution Non-Commercial
License (httr:///creativecommons.org/licenses/by-nc/3.0) which permits unrestricted noncommercial use, License (http://creativecommons.org/licenses/lby-nc/3.0) which permits unrestricted
distribution, and reproduction in any medium, provided the original work is properly cited.

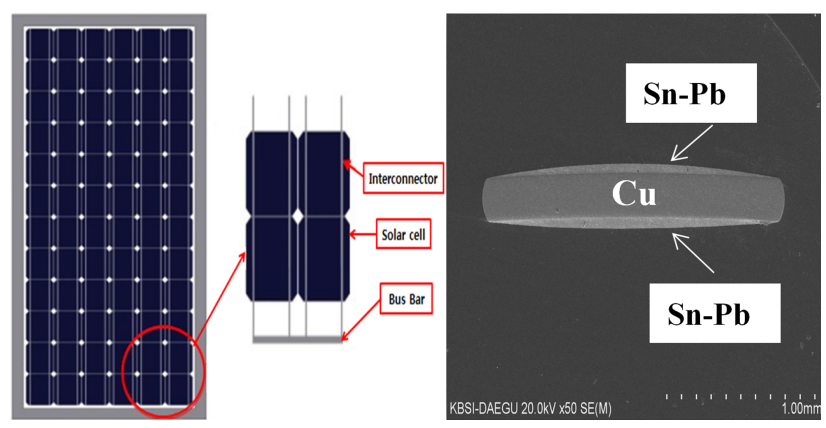

Fig. 1. Schematic diagram of solar cells and ribbon in a solar module and an SEM micrograph of the interconnector ribbon's crosssection.

ricated through the solution plating of lead-containing solders $(\mathrm{Sn}-\mathrm{Pb})$ on the internal $\mathrm{Cu}$ ribbon [10]. The extension of a solar module's lifespan of over 20 years is one of the most important issues in the research areas of solar ribbons [11-13]. The existence of the primary $\alpha$-phases will decrease the adhesive strength 
between the solar ribbon and the cell, consequently decreasing the lifespan of the solar ribbon [14-16]. This study focuses on the relationship between the surface smoothness of the internal $\mathrm{Cu}$ ribbon and the morphology of the $\mathrm{Sn}-\mathrm{Pb}$ plating layer for solar modules. The restriction of the primary $\alpha$-phase's formation was enabled by enhancing the smoothness of the surface of the internal $\mathrm{Cu}$ ribbon.

\section{EXPERIMENTS}

We analyzed the interconnector and bus-bar $\mathrm{Cu}$ ribbon samples with products currently being used. We used the interconnector $\mathrm{Cu}$ ribbon, of which the thickness was about $200 \mu \mathrm{m}$, and width was about $2.0 \mathrm{~mm}$. We also used the $\mathrm{Cu}$ wire by making the diameter from $2.0 \mathrm{~mm}$ to 0.5 by calendering. The plating composition of the Sn-Pb solder used was $60 \mathrm{wt} \% \mathrm{Sn}-40 \mathrm{wt} \% \mathrm{~Pb}$ near the eutectic composition. The solution plating temperature was maintained at $240{ }^{\circ} \mathrm{C}$ by using a plating bath. The thickness of the $\mathrm{Sn}-\mathrm{Pb}$ plating layer was about $15 \sim 30 \mu \mathrm{m}$, by controlling the plating rate and time.

The surface and cross-section morphology of the solar and $\mathrm{Cu}$ ribbons was observed using a scanning electron microscope (SEM; Hitach, S-4800). The composition of the surface and crosssection of the $\mathrm{Sn}-\mathrm{Pb}$ plating layer was also analyzed using energy dispersive spectroscopy (EDS; Hitach, S-4800). The thickness of the $\mathrm{Sn}-\mathrm{Pb}$ plating layers was measured in the cross-section SEM micrograph. The crystal structure of the $\mathrm{Sn}-\mathrm{Pb}$ plating layer was analyzed by using an x-ray diffractometer (XRD; PHILIPS, X'pert $\mathrm{APD})$. In addition, the adhesive strengths of pure $\mathrm{Pb}$ and $\mathrm{Sn}$ were measured using an adhesive strength tester.

\section{RESULTS AND DISCUSSION}

Figure 2 shows the $\mathrm{x}$-ray diffraction profile of the Sn60-Pb40 (wt\%) solder. We observed the crystalline $\mathrm{Sn}(200), \mathrm{Pb}(111)$, $\mathrm{Sn}(101)$, and $\mathrm{Pb}(200)$ reflections. However, a $\mathrm{Sn}-\mathrm{Pb}$ alloy phase was not observed. This indicates that the crystalline $\mathrm{Sn}$ and $\mathrm{Pb}$ phases in the solder existed separately.

Irregular reflection of light was observed on the surface of the interconnector ribbon for solar cell modules currently being used. In order to investigate the phenomenon of the light's irregular reflection, we observed the surface morphology of the interconnector ribbons using SEM. Figure 3 shows SEM surface micrographs of the interconnector ribbon with different magnifications. Generally speaking, the irregular reflection of light is caused by a bumpy surface [17]. Irregular reflection occurs from a bumpy surface, while regular reflection occurs from a smooth surface [17]. As a result of SEM, a noticeably bumpy surface was observed on the surface of the interconnector ribbon. The irregular reflection of light occurred near the bumpy surface area of the interconnector ribbon. As shown in Fig. 3(f), large primary $\alpha$-phases existed on the convex surface of the interconnector ribbon's plating layer. The diameter of the primary $\alpha$-phases was about $8.5 \mu \mathrm{m}$. Normal eutectic $\alpha$-phases were observed around the primary $\alpha$-phase, of which the diameter was small, ranging from about 1 to $2 \mu \mathrm{m}$. This result indicates that a bumpy surface of the interconnector ribbon near the large primary $\alpha$-phase caused an irregular reflection of light.

Irregular reflection of light was also observed on the surface of bus-bar ribbon for the solar cell modules currently being used Figure 4 shows SEM surface micrographs of the bus-bar ribbon with different magnifications. As a result of SEM, a noticeably bumpy surface was also observed on the surface of the bus-bar ribbon. As illustrated in Fig. 4(f), large primary $\alpha$-phases existed

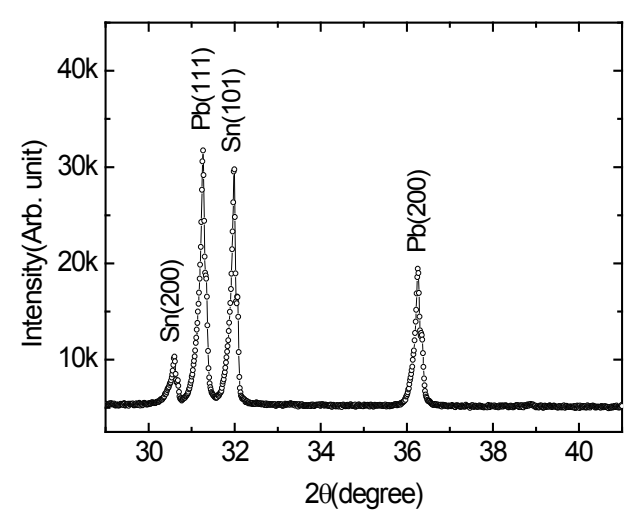

Fig. 2. X-ray diffraction profile of $\mathrm{Sn}_{60}-\mathrm{Pb}_{40}$ (wt\%) solder.
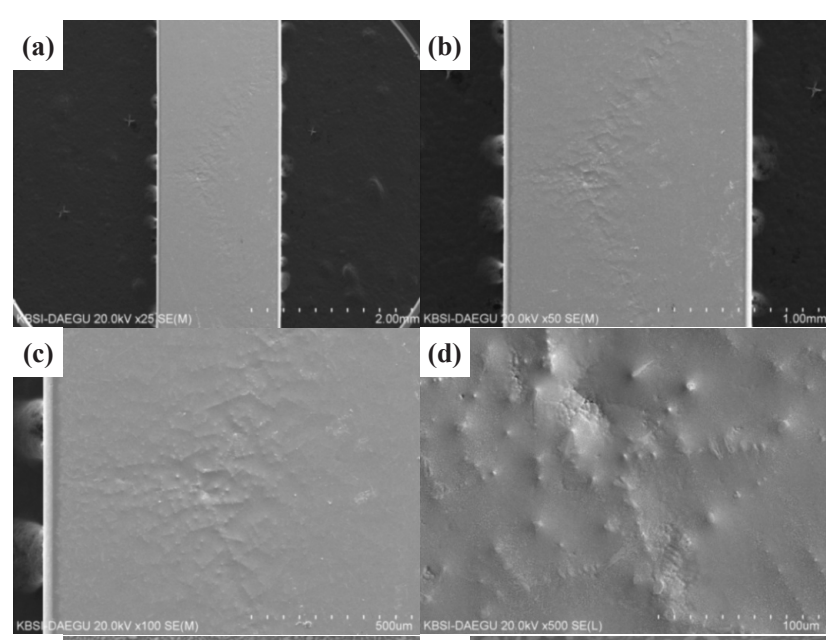

(e)

(d)

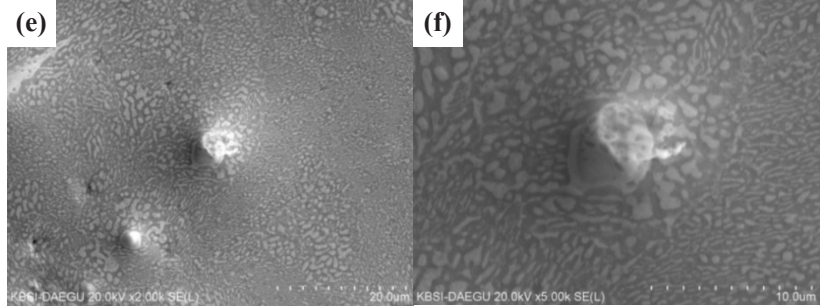

Fig. 3. SEM surface micrographs of interconnector ribbon for solar cell modules currently being used with different sizes of scale bars; (a) $2 \mathrm{~mm}$, (b) $1 \mathrm{~mm}$, (c) $500 \mu \mathrm{m}$, (d) $100 \mu \mathrm{m}$, (e) $20 \mu \mathrm{m}$, and (f) $10 \mu \mathrm{m}$.

on the convex surface of the plating layer of the bus-bar ribbon. The diameter of the primary $\alpha$-phases was about $9.0 \mu \mathrm{m}$. Normal eutectic $\alpha$-phases were also observed around the primary $\alpha$-phase. These results between the interconnector and the busbar ribbons are very similar to those in surface morphology, showing the existence of bumpy surfaces and large primary $\alpha$-phases.

We predicted that the bumpy surface of the plating layer of the solar ribbon has a close relationship with the surface roughness of the internal $\mathrm{Cu}$ ribbon. In order to reveal the internal structure of the large primary $\alpha$-phases, we observed the cross-sections of the interconnector ribbon by SEM. Figure 5(a) shows an SEM cross-section micrograph of the interconnector ribbon near the convex surface. We used the internal $\mathrm{Cu}$ ribbon, of which the thickness was about $200 \mu \mathrm{m}$, and width was about $2.0 \mathrm{~mm}$. The large primary $\alpha$-phase existed below the convex surface of the $\mathrm{Sn}-\mathrm{Pb}$ plating layer (white arrow). The primary $\alpha$-phase passed from the surface of the internal $\mathrm{Cu}$ ribbon to the convex surface 

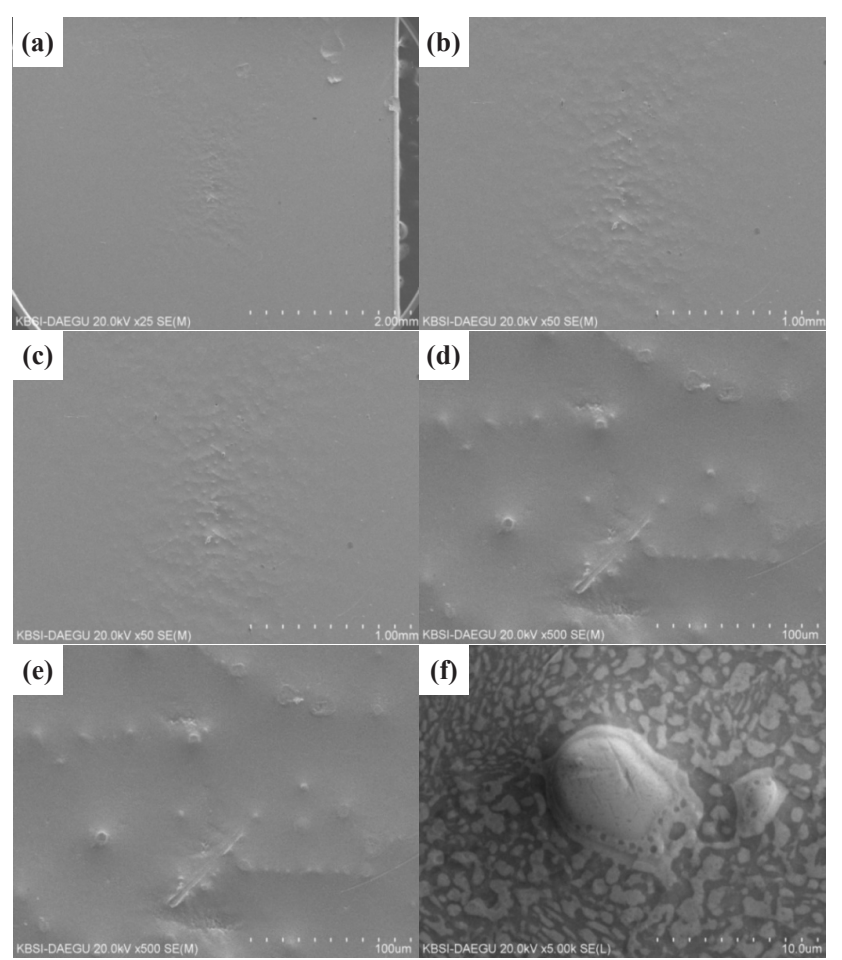

Fig. 4. SEM surface micrographs of bus-bar ribbon for solar cell modules currently being used with different sizes of scale bar; (a) $2 \mathrm{~mm}$, (b) $1 \mathrm{~mm}$, (c) $500 \mu \mathrm{m}$, (d) $100 \mu \mathrm{m}$, (e) $20 \mu \mathrm{m}$, and (f) $10 \mu \mathrm{m}$.

of the plating layer. The thickness of the $\mathrm{Sn}-\mathrm{Pb}$ plating layer was about $15 \mu \mathrm{m}$. The size of the primary $\alpha$-phase in the normal direction was about $15 \mu \mathrm{m}$, which is similar to the thickness of the plating layer. Meanwhile, the size of the primary $\alpha$-phases in the plain direction was about $8 \mu \mathrm{m}$, which is similar to the diameter of the primary $\alpha$-phases observed in Fig. 3(f).

It is notable that the size of the large primary $\alpha$-phase in the normal direction was very similar to the plating layer's thickness. In actual practice, the nucleation rarely occurs homogeneously, but rather occurs heterogeneously on surfaces [18]. Therefore, the bumpy surface of the internal $\mathrm{Cu}$ ribbon is able to easily act as site for the heterogeneous nucleation of primary $\alpha$-phases during the cooling of the $\mathrm{Sn}-\mathrm{Pb}$ melt solutions. We considered that the primary $\alpha$-phases heterogeneously nucleated on the bumpy surface of the internal $\mathrm{Cu}$ ribbon, and then largely grew to the surface of the $\mathrm{Sn}-\mathrm{Pb}$ plating layer [18].

Figure 5(b) shows the EDS cross-section mapping images of the composition of a interconnector ribbon, which was acquired from the SEM cross-section micrograph of Fig. 5(a). The compositions of $\mathrm{Sn}, \mathrm{Pb}$, and $\mathrm{Cu}$ (red, green, and blue, respectively) are shown in Figs. 5(c), 5(d), and 5(e). As shown in Fig. 5(d), the large primary $\alpha$-phase is clearly a Pb-rich phase. This result is consistent with the theoretical composition of primary $\alpha$-phase, 19.2 wt\% Sn-80.8 wt\% $\mathrm{Pb}[19,20]$. The melting temperature of $\mathrm{Pb}$, $327^{\circ} \mathrm{C}$, is $95^{\circ} \mathrm{C}$ higher than that of $\mathrm{Sn}, 232^{\circ} \mathrm{C}$, and is $144^{\circ} \mathrm{C}$ higher than that of the eutectic temperature of $\mathrm{Sn}-\mathrm{Pb}, 183^{\circ} \mathrm{C}[19,20]$. The eutectic structure is composed of a eutectic $\alpha$-phase and $\beta$-phase, and the eutectic composition is $61.9 \mathrm{wt} \% \mathrm{Sn}-38.1 \mathrm{wt} \%$ $\mathrm{Pb}[19,20]$. The large, Pb-rich, primary $\alpha$-phases can cause a decrease of the adhesive strength between the ribbon and cell, compared to that of the eutectic structure. The adhesive strength of pure $\mathrm{Pb}$ was very small at $81 \mathrm{~N} / \mathrm{mm}^{2}$, compared to that of pure $\mathrm{Sn}, 218 \mathrm{~N} / \mathrm{mm}^{2}$. Also, the resistivity of pure $\mathrm{Pb}$ was very large at $208 \mathrm{n} \Omega \cdot \mathrm{m}$, compared to that of pure Sn, $115 \mathrm{n} \Omega \cdot \mathrm{m}$. Therefore, the
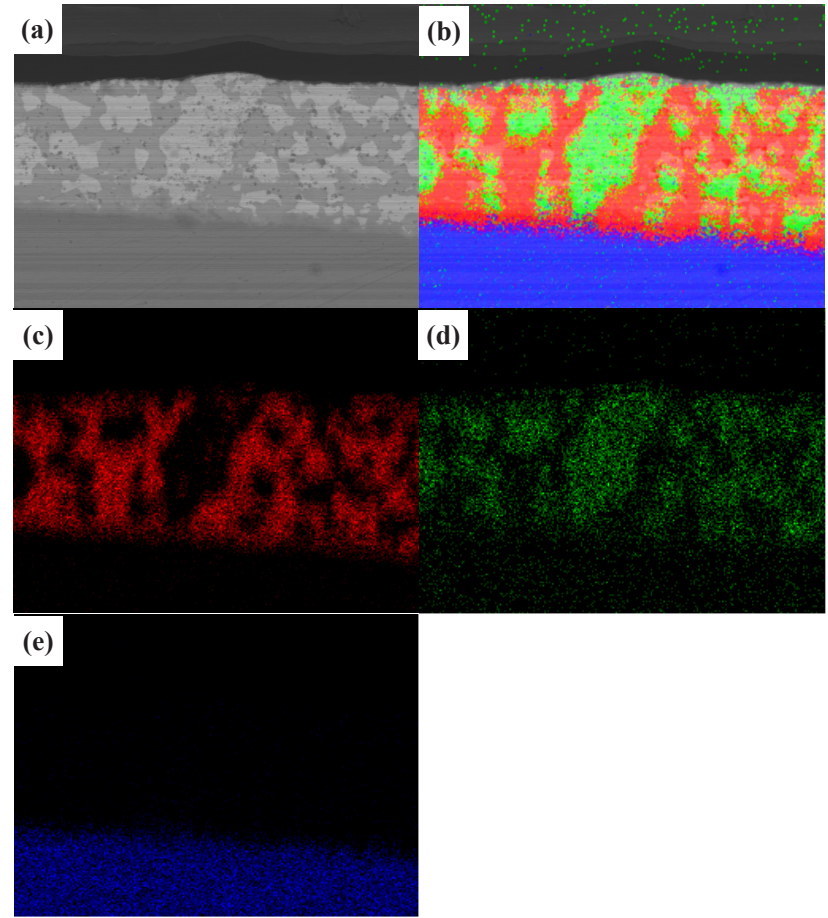

Fig. 5. (a) SEM cross-section micrograph of an interconnector ribbon currently being used. EDS cross-section mapping images of the interconnector ribbon's composition; (b) total, (c) $\mathrm{Sn}$, (d) $\mathrm{Pb}$, and (e) $\mathrm{Cu}$.
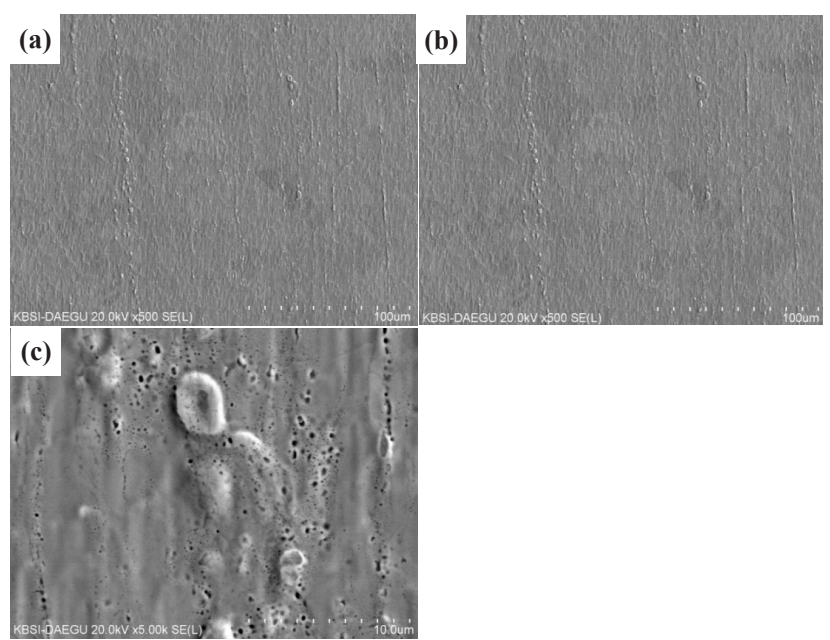

Fig. 6. SEM surface micrographs of pure Cu ribbon for solar cell modules currently being used with different sizes of scale bars; (a) $100 \mu \mathrm{m}$, (b) $20 \mu \mathrm{m}$, and (c) $10 \mu \mathrm{m}$.

existence of the large primary $\alpha$-phases can significantly reduce the lifespan and increase the contact resistance of the $\mathrm{Cu}$ ribbon for solar modules.

In order to confirm the existence of the bumpy surface of the internal $\mathrm{Cu}$ ribbon, we carefully observed the surface morphology of the Cu ribbon. Figure 6 shows the SEM surface micrographs of pure $\mathrm{Cu}$ ribbon for solar cell modules currently being used, with different magnifications. As a result of SEM, a bumpy surface with convex parts was observed on the surface of the pure $\mathrm{Cu}$ ribbon. As illustrated in Fig. 6(c), the diameter of the convex parts of the surface of the pure $\mathrm{Cu}$ ribbon was about $2 \sim 5 \mu \mathrm{m}$. We believed that the convex parts near the internal $\mathrm{Cu}$ ribbon's surface act as the main heterogeneous nucleation sites of the large 


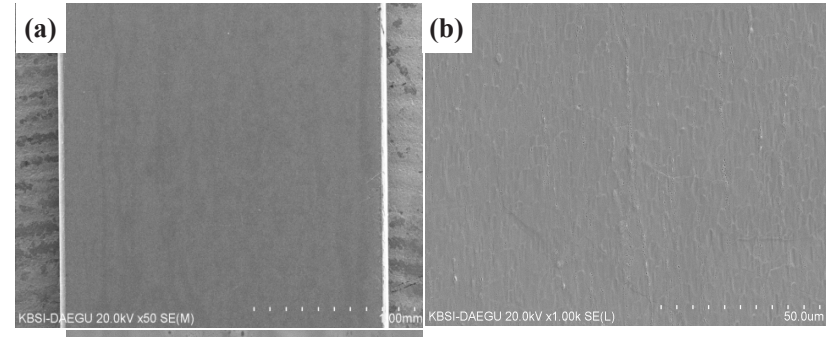

(c)

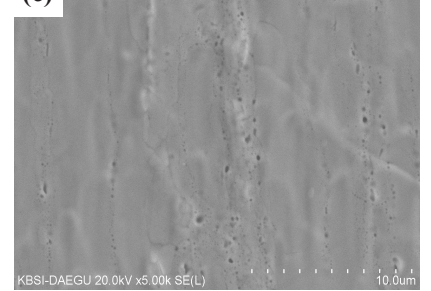

Fig. 7. SEM surface micrographs of pure Cu ribbon having enhanced smoothness with different sizes of scale bar; (a) $100 \mu \mathrm{m}$, (b) $20 \mu \mathrm{m}$, and (c) $10 \mu \mathrm{m}$

primary $\alpha$-phases.

We have enhanced the smoothness of pure $\mathrm{Cu}$ ribbon by improving the surface smoothness of the press roller during the calendering of $\mathrm{Cu}$ wire. We also chose a $\mathrm{Cu}$ wire that has an excellent surface smoothness. Figure 7 shows SEM surface micrographs of pure $\mathrm{Cu}$ ribbon having enhanced smoothness with different magnifications. As a result of SEM, we could observe the internal $\mathrm{Cu}$ ribbon's smooth surface with almost no convex parts.

With the internal pure $\mathrm{Cu}$ ribbon having enhanced smoothness, we fabricated the interconnector ribbon in the same condition. Figure 8 shows the SEM surface micrographs of the interconnector ribbon with different magnifications. After $\mathrm{Sn}-\mathrm{Pb}$ plating on the smooth internal $\mathrm{Cu}$ ribbon, the surface smoothness of the interconnector ribbon was improved by restricting the formation of the large primary $\alpha$-phases. We confirmed that the solar ribbon's surface smoothness depends on the internal $\mathrm{Cu}$ ribbon's surface smoothness.

\section{CONCLUSIONS}

We studied the relationship between the surface smoothness of a Cu ribbon and the surface/cross-section morphology of a $\mathrm{Sn}-\mathrm{Pb}$ plating layer for solar modules. From the result of SEM, a bumpy surface was observed on the surface of the solar ribbon, which caused irregular reflection of light. Large, $\mathrm{Pb}$-rich, primary $\alpha$-phases were found below the convex surface of the solar ribbon, passing from the surface of the internal $\mathrm{Cu}$ ribbon to the surface of the $\mathrm{Sn}-\mathrm{Pb}$ plating layer. The size of the large primary $\alpha$-phase in the normal direction was about $15 \mu \mathrm{m}$, which is similar to the thickness of the plating layer, and in the plain direction was about 8 9 $\mu \mathrm{m}$. The primary $\alpha$-phases heterogeneously nucleated on the internal $\mathrm{Cu}$ ribbon's convex surface, and then largely grew to the convex surface of the $\mathrm{Sn}-\mathrm{Pb}$ plating layer. The existence of the primary $\alpha$-phases will decrease the adhesive strength between the solar ribbon and cell, consequently decreasing the lifespan of the solar ribbon. The restriction of the primary $\alpha$-phase's formation was enabled by enhancing the smoothness of the surface of the internal Cu ribbon; it was also possible to increase the adhesive strength and decrease the contact resistance. We confirmed that the surface smoothness of the solar ribbon
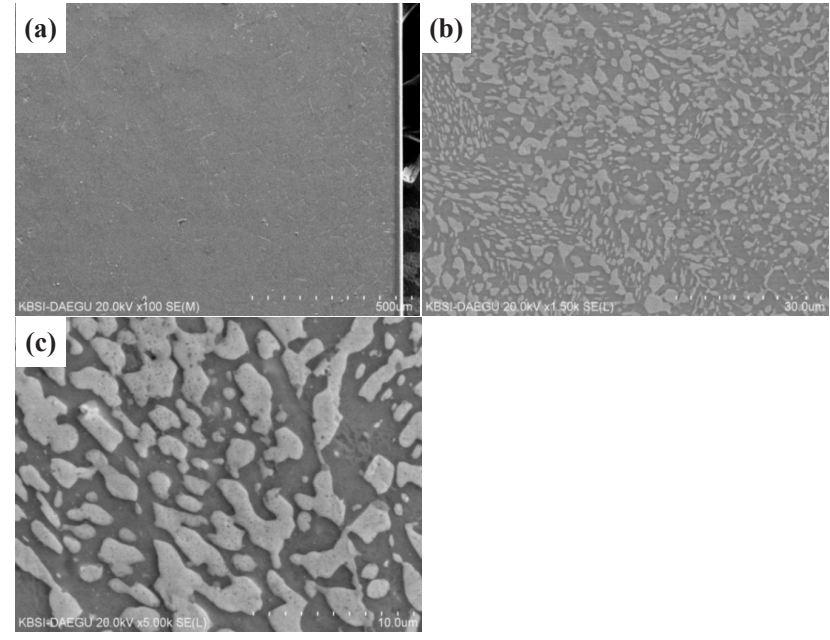

Fig. 8. SEM surface micrographs of interconnector ribbon having enhanced smoothness of internal Cu ribbon with different sizes of scale bars; (a) $500 \mu \mathrm{m}$, (b) $30 \mu \mathrm{m}$, and (c) $10 \mu \mathrm{m}$.

depends on the surface smoothness of the internal $\mathrm{Cu}$ ribbon.

\section{ACKNOWLEDGMENTS}

This research was financially supported by the Ministry of Trade, Industry \& Energy, Korea Institute for Advancement of Technology, DaeGyeong Insitute for Regional Program Evaluation, and Sanko Korea through the Leading Industry Development for Economic Region, Korea. This work was also supported by the Kyungpook National University Research Fund. The author also acknowledges Mr. K. J. Hwang for his contributions to SEM-EDS experiments in the Korea Basic Science Institute (Daegu Center).

\section{REFERENCES}

[1] H. H. Manko, Solders and Soldering (McGraw-Hill, New York, 2001), p. 2-13, p. 21-27.

[2] D. M. Bagnall and M. Boreland, Energy Policy, 36, 4390 (2008). [DOI: http://dx.doi.org/10.1016/j.enpol.2008.09.070].

[3] M. N. Islam, Y. C. Chan, M. J. Rizvi, and W. Jillek, J. Alloys Comp., 400, 136 (2005). [DOI: http://dx.doi.org/10.1016/ j.jallcom.2005.03.053].

[4] C. Y. Liu, C. Chen, and K. N. Tu, J. Appl. Phys., 88, 5703 (2000). [DOI: http://dx.doi.org/10.1063/1.1319327].

[5] J. H. Lee, Y. H. Lee, and Y. S. Kim, Scripta Materialia, 42, 789 (2000). [DOI: http://dx.doi.org/10.1016/S1359-6462(99)004315].

[6] M. N. Islam, Y. C. Chan, A. Sharif, and M. O. Alam, Microelectron. Reliab., 43, 2031 (2003). [DOI: http://dx.doi.org/10.1016/ S0026-2714(03)00190-2].

[7] M. N. Islam, A. Sharif, and Y. C. Chan, J. of Electron. Mater., 34, 143 (2005). [DOI: http://dx.doi.org/10.1007/s11664-0050225-z].

[8] Satyanarayan and K. N. Prabhu, Advanced in Colloid and Interface Science, 166, 87 (2011)

[9] R. Lathrop and K. Pfluke, 26th European Union Solar Energy Conf., (2011).

[10] M. Schaefer, R. A. Fournelle, and J. Liang, J. of Electronic Materials, 27, 1167 (1998). [DOI: http://dx.doi.org/10.1007/s11664998-0066-7]. 
[11] W. Sinke, Renewable Energy World (2008).

[12] A. Henckens, H. Goossens, European Coatings Journal (2010).

[13] I. J. Bennett, 22th European Photovoltaic Solar Energy Conf. (2007).

[14] C. Y. Liu, J. Appl. Phys., 88, 5703 (2000). [DOI: http://dx.doi. org/10.1063/1.1319327]

[15] H. H. Hsieh, F. M. Lin, and S. P. Yub, Sol. Energ. Mat Sol. C., 95, 39 (2010). [DOI: http://dx.doi.org/10.1016/ j.solmat.2010.04.034].

[16] H. H. Hsieh, F. M. Lin, F. Y. Yeh, and and M. H. Lin, Sol. Energ Mat. Sol. C., 93, 864 (2009). [DOI: http://dx.doi.org/10.1016/ j.solmat.2008.10.005].

[17] D. K. Perovich, J. of Geophysical Research, 99, 3351 (1994). [DOI: http://dx.doi.org/10.1029/93JC03397].

[18] F. Ziese, G. Maret, and U. Gasser, J. of Physics: Condensed Matter., 25, 375105 (2013). [DOI: http://dx.doi.org/10.1088/0953$8984 / 25 / 37 / 375105]$.

[19] J. E. Spinelli, I. L. Ferreira, and A. Garcia, J. Alloy. Compd., 384, 217 (2004). [DOI: http://dx.doi.org/10.1016/ j.jallcom.2004.04.098].

[20] D. Gupta, K. Vieregge, and W. Gust, Acta Materialia, 47, 5 (1998). [DOI: http://dx.doi.org/10.1016/S1359-6454(98)00348-6]. 